THURSDAY, MAY 13, I 875

\section{LORD HARTISMERE'S VIVISECTION BILL}

THE Bill brought forward in the Upper House by 1 Lord Hartismere for regulating the practice of Vivisection deserves special attention on account of its being the first important legislative attempt to restrict the prosecution of physiological research.

It enacts that it shall not be lawful for anyone to perform a vivisection except in a place which is registered in pursuance of the proposed Act, the registration being in such form and under the management of such persons as the Secretary of State shall appoint. The registration. certificate is to be renewed once a year; it may be cancelled at any time on its being proved that any provision of the Act has been contravened, and the place registered may be visited at any time by any inspector of anatomy. Complete anæsthesia is compulsory, and curare is not to be deemed to be an anæsthetic. The Secretary of State may grant special licenses for the performance of vivisections in which anæsthetics are not employed; there shall be paid in respect of every such license a sum not exceeding ten pounds, and each license is to continue in force for six months.

In the framing of this Bill there is a serious misrepresentation of the true requirements of the case, The source of error lies in the fact that it is taken for granted that there is only a single class of physiological workers. Such, however, is not the case; there are two distinct classes, and although we agree with the tenor of the Bill as far as one class is concerned, we are certain that it would so severely affect the other that its results would be seriously,detrimental to the prosecution of physiological research in this country.

Among ourselves there are several scientific men who devote part of their life to the study of the problems of the vital mechanism. Some do so from the inherent interest of the subject; others from a desire to obtain a further insight into pathology and disease generally. In the course of their investigations it is now and then absolutely essential for the completion of a line of argument, or for the acquisition of the knowledge of the collateral phenomena attending some previously recorded result, that an experiment or experiments should be performed on a living animal. Those whose mental development leads them to conduct investigations of this character are frequently peculiarly unwilling to do so in public institutions. It is their spare minutes, when they are entirely their own masters, that they employ in their favourite study. Are they to be compelled, against their natural dispositions, either to obtain an official license for the performance of these experiments on their own premises, or, as an alternative, conduct them in some previously specially licensed establishment which is under the control of others? The necessity for such a method of procedure would deter many an excellent worker from commencing investigations which he recognises to be so much impeded by legal restrictions. There might as well be a tax on astronomers directing their telescopes to any special planet or to the moon. The public may feel certain that students of the class to which we refer will never go beyond the limits of the innate laws of sympathy present in all civilised humanity. Such do the most valuable work in a scientific point of view ; and any legislative measure which in any way affects them injuriously, either by rendering the whole research apparently too formidable at the outset, or by the introduction of unpleasant details during its prosecution, ought most strenuously to be resisted. The power of turning to a practical end the results of inductive reasoning is the basis of the British nature. Inductive research cannot be had for money; it is always a labour of love ; it is not fair to put impediments in the way of it.

The class of physiologists to whom legislative restrictions with regard to vivisection do apply, is the teachers. There is no doubt that those who assert that the performance of vivisectional demonstration is unnecessary will have the sympathy of the majority. A fact may be learned from books or by practical demonstration. As far as natural science goes, the extra time which has to be expended in obtaining the results practically is generally quite made up for by the accessory details introduced, which are many of them omitted in written or verbal descriptions. Observation is a far more sound basis on which to start fresh work than the knowledge acquired from books alone. The student should therefore, where nothing counter indicates, have the opportunity of repeating, on his own account, the experiments he reads of. In the case of practical physiology, however, another consideration has to be introduced. Here the subjects of experiment are sentient beings, and the question comes to be whether the advantages of the practical verification of fully described phenomena which involve pain are counterbalanced by the injustice done in the production of the pain itself. We think not, and are therefore fully in favour of legislative restrictions on the powers of those who wish to employ living animals for the purpose of demonstration, even where anæsthetics are employed, because there is a tendency among those who are in the habit of repeating experiments to neglect those parts of them which are not absolutely necessary. But any measure which in any way impedes original work, as does the Bill before us, ought, in our opinion, to be strongly opposed.

\section{GEIKIE'S "LIFE OF MURCHISON"*}

II.

Life of Sir Roderick I. Murchison, Bart., F.R.S. etc. Based on his Fournals and Letters. With Notices of his Scientific Contemporaries and a Sketch of the Rise and Growth of Palcozoic Geology in Britain. By Archibald Geikie, LL.D., F.R.S., Director of H.M. Geological Survey of Scotland, and Murchison Professor of Geology and Mineralogy in the University of Edinburgh. 2 vols. Illustrated with Portraits and Woodcuts. (London: John Murray, 1875.)

M R. MALLET, in a memoir published in the Philo2V sophical Transactions (vol. $\mathrm{x}_{3}$, p. 147), which has attracted attention as much for the boldness of its tone as for anything else, has laid down the dictum that no sound progress can be made in geology unless the investigator be also mathematician, chemist, and physicist. Now, Murchison was none of these, yet he would be a

* Continued from p. 3 . 